\title{
Short-Term Load Forecasting for a Captive Power Plant Using Artificial Neural Network
}

\author{
Vidhi Tiwari, Gautam Buddha University, India \\ (iD) https://orcid.org/0000-0003-3059-6784 \\ Kirti Pal, Gautam Buddha University, India
}

\section{ABSTRACT}

The irregularity of the Indian grid system increases with the increase in the power demand. The quality of power supplied by the power grid is also poor due to continuous variation in frequency and voltage. To overcome this problem of power deficit, captive power plants installed capacity has grown at a faster rate. Here, short-term load forecasting of Yara Fertilizers India Private limited installed at Babrala, Uttar Pradesh is performed using multi-layer feed-forward neural network in MATLAB. The algorithm used is a Levenberg Marquardt algorithm. However, the training and results from ANN are very fast and accurate. Inputs given to the neural network are time, ambient air temperature from the compressor, cool air temperature at the compressor, and IGV opening. The need, benefits, and growth of CPP in India and use of ANN for short-term load forecasting of CPP has been explained in detail in the paper.

\section{KEYWORDS}

Artificial Intelligence, Back Propagation Algorithm, Combined Cycle Power Plant, Gas Turbine, Heat Recovery Steam Generator, Inlet Guide Vane, Levenberg-Marquardt Back-Propagation, Yara Fertilizers Limited

\section{INTRODUCTION}

Electricity has now becone a part of everyone's life. In India, demand is increasing day by day and also facing problems such as power quality issue, lack of latest technology, losses etc. Stress on existing energy resources has also increased drastically due to increase in electricity demand and thus, leads to shortage of power. Now-a-days demand of CPP is increasing day by day due to its various advantages such as high efficiency, low environmental impact, low investment cost, simple operation and many more.

The load demand prediction and generation of CPP must be accurate. Electrical load Prediction is the process of future load prediction in the blocks of hours, days, weeks, months or for a year. It is mainly done in order to prognosticate the power consumption of electrical utilities and help them to plan their future decisions related to Generation, Transmission and Distribution system. Electrical load prediction also helps in managing demand and supply of electricity at every moment which is managed by utilities. Load forecasting is used for power supply planning, transmission \& distribution

\section{DOI: 10.4018/IJIRR.289613}

This article published as an Open Access article distributed under the terms of the Creative Commons Attribution License (http://creativecommons.org/licenses/by/4.0/) which permits unrestricted use, distribution, and production in any medium, provided the author of the original work and original publication source are properly credited. 
planning, demand side management, maintenance and financial planning. So accurate load prediction is very essential for the effective working of the power system otherwise it may leads to the equipment's failure and supply loss (Jaswal, 2013).

An author (Alam et al., 2013; Oak \& Patil, 2016) presented case study of the captive power plant in Maharashtra and Bangladesh respectively. A study by (David et al., 2004) has shown that the scenario of captive power plants in India can be broadly assigned to (a) manage the backup power system, (b) checks the quality of the supply, (c) ensures the benefits of co-generation process of industries, and (d) also generate electricity at lower costs than the high industrial tariffs. In view of designing the Captive power generation from coolant jet author (Pooja et al., 2018) suggested some guidelines for executing the captive hydro power plant at low head of coolant jet for developers.

There are various factors which affect load forecasting such as weather variables (temperature, rain, wind and humidity), holidays, festivals, economic growth and new load demand (Gupta et al., 2013). The two main classification of load forecasting techniques are parametric and non-parametric. Examples of parametric technique are auto regressive moving average (ARMA), linear regression, general exponential technique and stochastic time series techniques. These techniques are also known as statistical or traditional techniques. The main limitations of traditional methods are its capability to cover up the changes due to environment. However, this can be is resolved by using non- parametric techniques. This method is also known as modern techniques as it uses artificial intelligence. Modern techniques include Neuro-Fuzzy Method, Artificial Neural network (ANN) method, Genetic algorithm (GA), Fuzzy logic method, and Particle swamp optimization (PSO). Among these methods of artificial intelligence based technique called artificial neural network is appeared to be most appropriate and has received attention of many researchers (Bello \& Harrison, 2015; Hippert, Pedreira, \& Souza, 2001; Karthikeyan et al., 2019). ANN has the capacity to make decisions for uncertain environment, to solve complex problems, image recognition, and prediction eapability. Thus ANN has emerged as a useful techniques as compared to the other traditional techniques. (Abiodun et al., 2018; Araque et al., 2017).

In hybrid networks, stochastic learning techniques like genetic algorithm (GA), particle swarm optimization (PSO) are applied in combination with the artificial neural network for short term load forecasting. An author (Baliyan et a1, 2015) has discussed about the various applications of several stochastic learning techniques with the artificial neural network for short term load forecasting. In the paper (He, 2017) author proposes an architecture of deep neural network for load forecasting of an hourly load of North China city. Deep neural network architecture is also used by other various authors for load forecasting (Grazian \& Xibilia, 2020; Li et al., 2019; Sun et al., 2019).

In the present work ANN is used for short term load prediction of Captive Power Plant, Yara Fertilizers Indsa Private limited installed at Babrala, Uttar Pradesh, India. The MATLAB tool box is used to train and predict the load using ANN. Section 2 describes about the Captive Power Plant component, section Sexplains the ANN technology which is used to predict the load demand of CPP. Results of proposed methodology are illustrated in section 6 and further conclusions are discussed.

\section{CAPTIVE POWER PLANT}

There are two types of power generation entities in India such as Generation Non-Utilities or Captive Power Plants (CPPs) and Generation Utilities. Captive Power Plant (CPP) is a power plant which is set up by any person in order to generate electricity for his own use. It is set up by any association of persons or co-operative society for their own consumption of electricity (Electricity Act, 2003) (Ministry of Power, 2003).After the introduction of the Electricity Act 2003,surplus power from captive plants, after meeting self-requirements, could be sold to third parties.(Tirthankar, 2010).

Yara fertilizer India Private limited, Babrala (captive Power plant) consist of two gas turbines units, two waste heat recovery boilers, steam and turbo pump, auxiliary electrical and mechanical 
Table 1. Gas turbine specifications

\begin{tabular}{|l|l|l|}
\hline 1. & Type & Impulse turbine \\
\hline 2. & Speed & $5178 \mathrm{rpm}$ \\
\hline 3. & Air inlet temperature & 45 degree Celsius \\
\hline 4. & Exhaust temperature of flue gases & 516 degree Celsius \\
\hline 5. & Exhaust pressure of flue gases & $756 \mathrm{~mm} \mathrm{Hg}$ \\
\hline
\end{tabular}

equipment's. The main plant block consists of two modules, each of 1 GTGs (Gas Turbine Generator) placed on each side and 1 HRSG (Heat Recovery Steam Generator).

\section{GAS TURBINE}

A rotating device in which the action of a fluid is used to produce work is called a Turbine. These fluids may be: helium, steam, air, wind, water and gas etc. Major components of gas turbine are air intake filter with evaporative cooler, the shaft driven compressor and the combustion chamber. A gas turbine mainly consist of a compressor which is used to extract air from the environment .In compressor air got compressed and then passes to the combustor. In combustor, fuel is added to the compressed air in order to increase its temperature. That hot air is then given to the turbine to extract power from the flow to hot air and get expanded. These Gas turbines are capable of attaining full load within 10 to 15 minutes. The operating speed of gas turbine is $5178 \mathrm{rpm}$ and other specifications are mentioned in table 1.

\section{WORKING OF COMBINED CYCLE POWER PLANT}

Here CPP is a combined cycle power plant which mainly consists of both the gas turbine and steam turbine to produce electricity. Atmospheric air is taken as the input for the compressor where air is compressed and then the air moves to the combustion chambers where it is ignited and that high temperature air moves to the gas turbine which drives a generator and hence electricity is produced.

Heat recovery steam generator (HRSG) captures the exhaust from the gas turbine which is further used to produce steam and that steam is used to drive the steam turbine in order to produce further additionarectricity. This whole system increases the overall efficiency. So from Figure 1, cool air temperature to the compressor is the air going into the compressor and ambient air temperature from the compressor is air coming out of the compressor and IGV is Inlet Guide Vane controls the air flow to the compressor in which air is allowed to flow at the proper angle.

\section{IMPLEMENTATION OF ANN FOR CAPTIVE POWER PLANT}

ANN is mainly composed of highly connected structure in order to process the information. Multilayer feed forward neural network is used for load forecasting as it can approximate nonlinear function with high accuracy. Selection of input and output data is very important for prediction (Bello et al., 2015). Input is given to the input layer, which is then given to the hidden layer where the information is processed and output from the hidden layer is finally given to the final layer which is called output layer. The ANN is a huge parallel implementation whose processing speed is very high and due which ANN has a great potential in the field of research (Hippert, Pedreira, \& Souza, 2001). Now-a-days ANNs is used for various applications such as natural language processing, image recognition, and many more. 


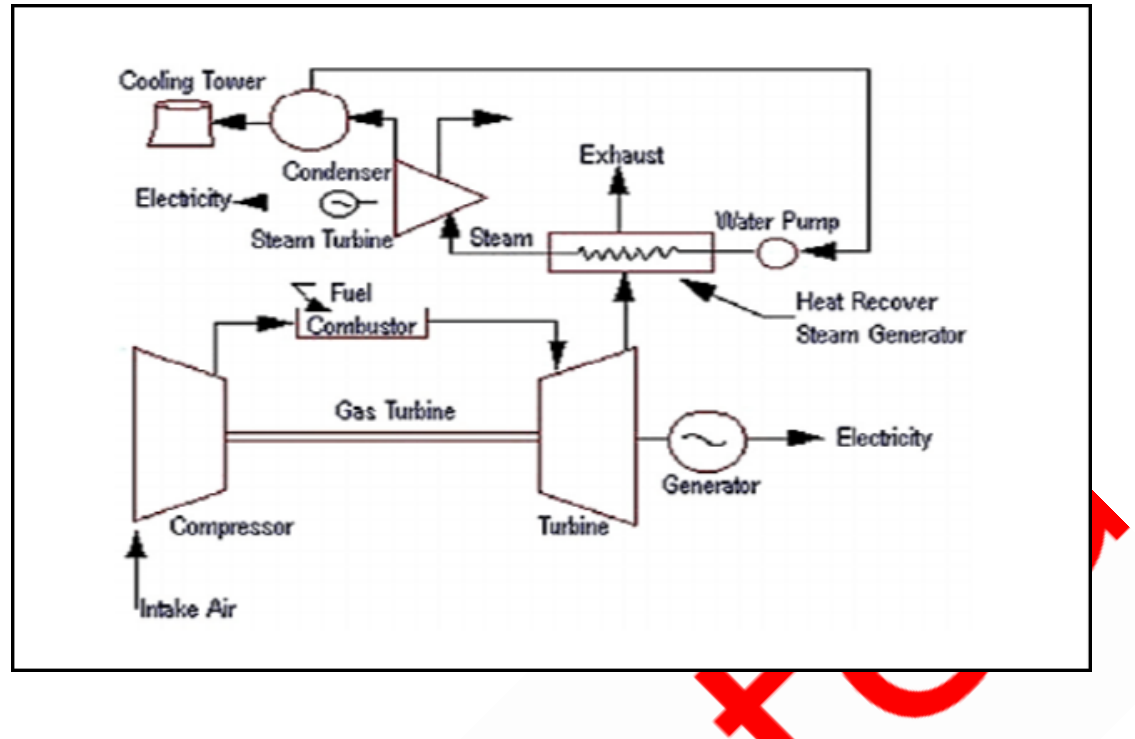

An ANN model made use of the Levenberg- Marquadt Back-Propagation two layer feed forward ANN model with the help of MALTAB which showed a high degree of accuracy in future load forecasting (Atlas et al., 1991). The most common algorithm is back propagation algorithm as it is fast, simple and easy to program. Back propagation algorithm is very flexible as well. AI can be extensively applied to in petroleum exploration andindustrial production (Abiodun et al., 2018) and business (Araque et al., 2017) setting for optimization. Since ANN model resembles to the functioning of human brain due to which its applications are increasing globally (Liu et al., 2017).

Figure 2 shows the block diagram of the overall model of feed-forward neural network which is trained by Levenberg-Marquardt Back Propagation algorithm. Data which is taken from Yara Fertilizersis of six months and that data are used for training, validation and testing. For training $70 \%$ data is used, $15 \%$ for validation and $15 \%$ for testing. For prediction, data is imported into Neural Network Toolbox of the MATLAB and prediction procedure is carried out to predict the load for the month of March 2020 and the network is trained with the past six month's data. From the, Figure 2 inputs given to the model are time, ambient air temperature from the compressor, cool air temperature at the compressor and the IGV opening from which forecasted load is obtained.

Two variables $X$ and $Y$ are created in the workspace of the MATLAB which are input and target data respectively. Both input and Target data is imported in the neural network toolbox. This is a feedforward network with two layer structure in which sigmoid activation function is used in hidden layer and linear activation function in output layers. This network is trained with Levenberg-Marquardt

Figure 2. Block diagram of ANN structure

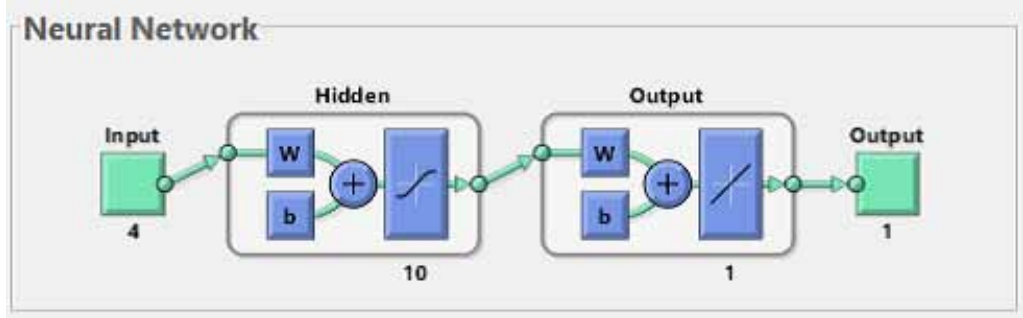



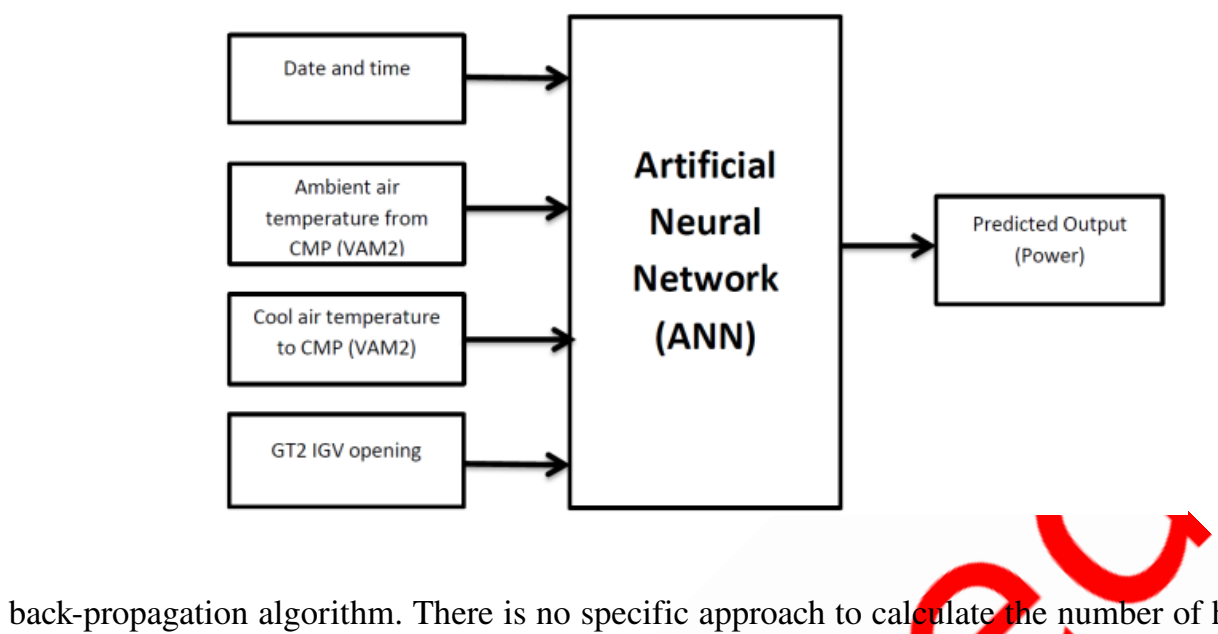
nodes and the numbers of neurons are taken as 10 .

\section{TRAINING AND TESTING RESULTS}

After training the network we have obtained the following results:

\subsection{Regression Plot}

Figure 4 shows the plot of regression, which mainly comprises of four plots as shown below. The regression plot is mainly the plot between set target and the output obtained from the network. In Figure 4, the first plot is the plot of the data which was set for Training, the second plot is the plot of data which was set for Validation, the third plot is the plot of the data which was set for testing and the forth plot is the overall plot of the network. From all the plots we can see that value of $\mathrm{R}$ is coming as 1 , which shows the accurate and reasonable good fit of data. So, the relationship between output obtained after training the network and the target is linear and accurate.

\subsection{The Performance Plot}

Performance plot is the plot between the number of epochs and Mean Squared Error (MSE). It mainly shows the performance of the network by showing Validation error, Train error and Test error. From the given plot, we can see that the result is reasonable as the final mean square error is extremely small. From the figure 5, at $6^{\text {th }}$ iteration the best validation performance of 0.00013282 is achieved.

\subsection{Error Histogram}

The figure 6 shows the plot of the error histogram in which Blue bars, Green Bar and Red bar represents Training data, Validation data and Testing data respectively. From the figure 6, it can be seen that most of the error fall between -0.02179 and 0.01845 .

\subsection{Training State Plot}

The Figure 7 shows the training state plot which mainly consists of three plots. The first plot is a plot between gradient and number of Epochs. The value of a gradient is obtained as 0.00062898 at 11 epochs. The second plot of Figure 7 is the plot between learning rate (mu) and the number of epochs and it can also be seen that with the increase in epochs mu decreases and becomes constant. It shows that with the increase in training process error of the network reduces. The value of mu is coming 
Figure 4. Regression Plot
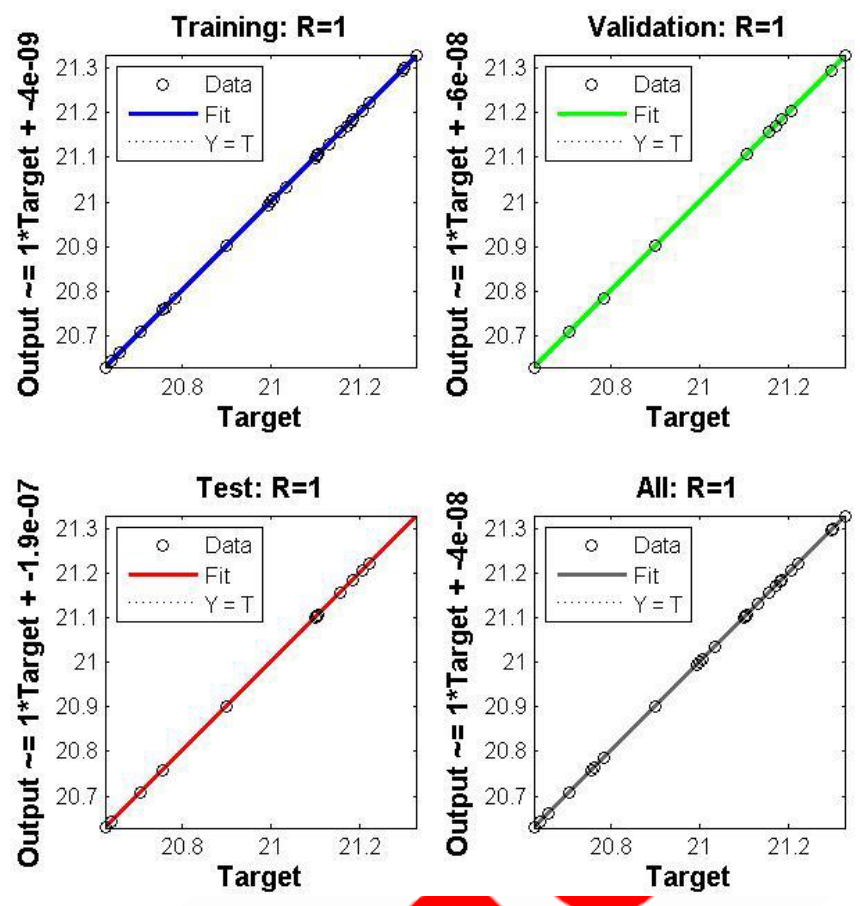

All: $\mathbf{R}=\mathbf{1}$

Figure 5. Performance plot

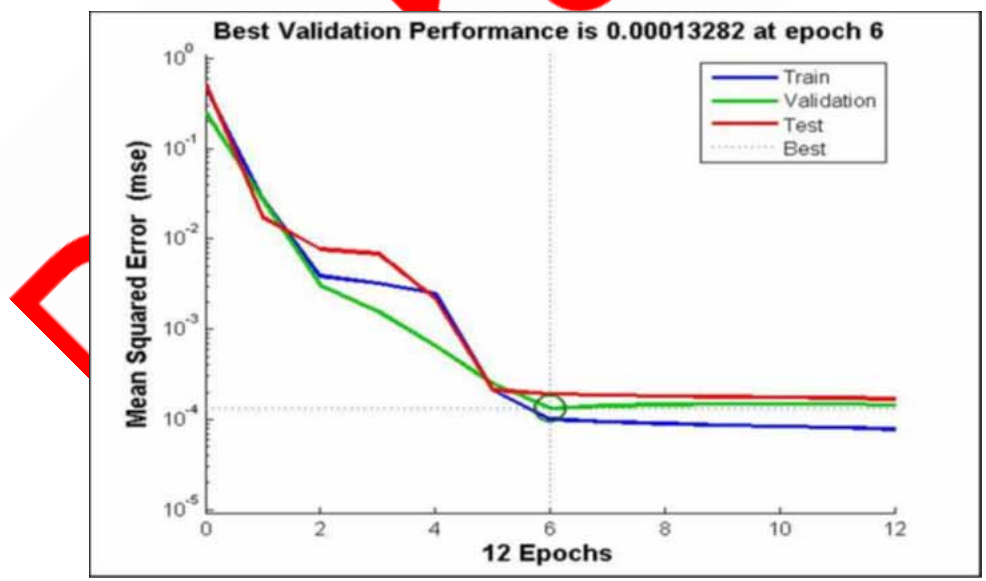

as $1 \mathrm{e}-05$ at 11 epochs. The third plot of Figure 7 performs a validation check which is coming as 6 at 11 epochs.

\subsection{Comparison Between the Predicted Load and Actual Load}

The Figure 8 shows the plot between Predicted Load in Megawatt (Output) after the training of the network and the actual load for the month of March 2020.The graph mainly consist of the two plots. The Red line plot shows the predicted load and the blue line plot shows the Actual load (Target) which is given for training as a target to the neural network. 
Figure 6. Error Histogram

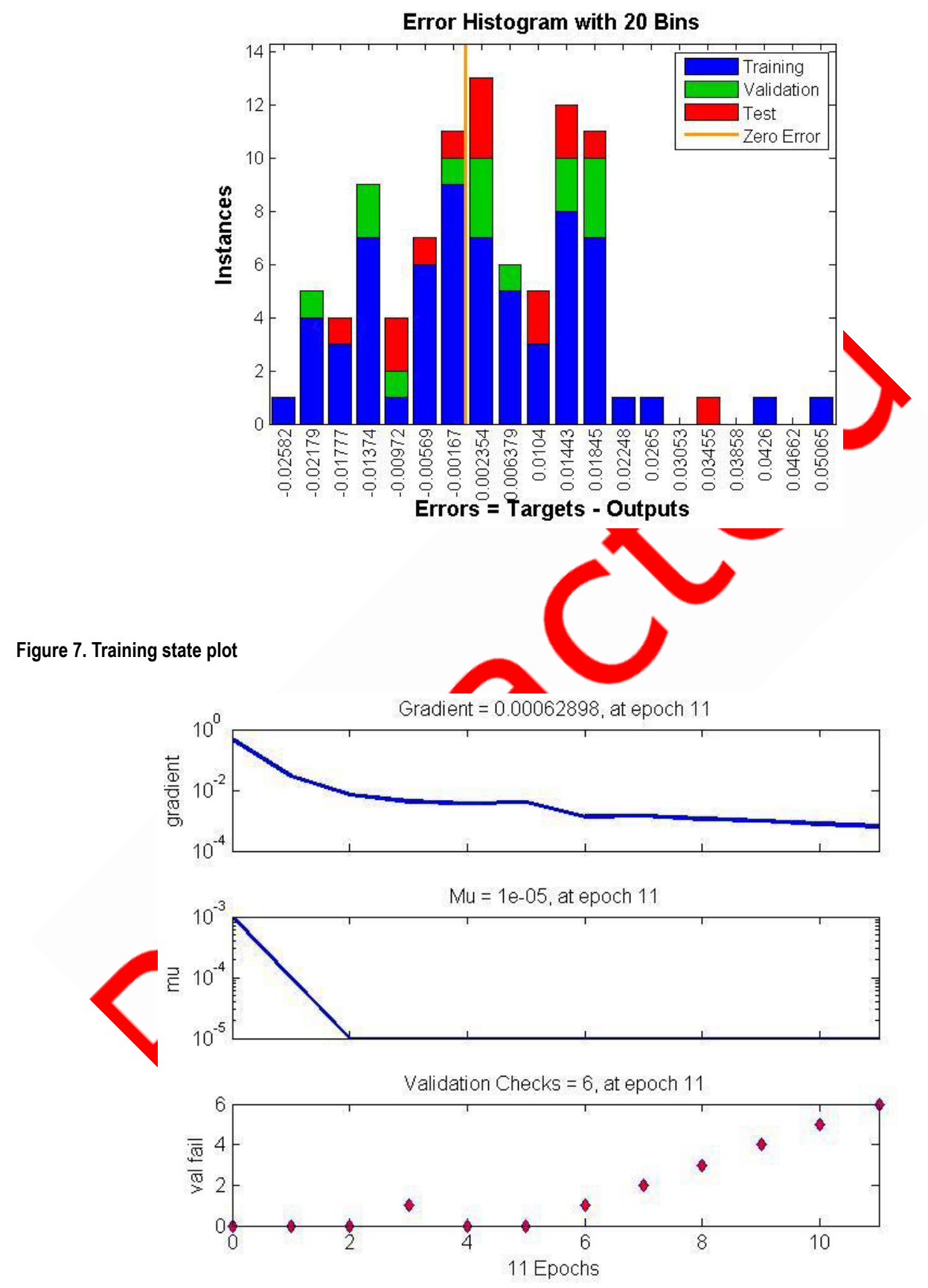

From the Figure 8 it can be seen that both plots of the actual load and predicted load are almost overlapping which shows that there is very less deviation between the predicted load and the actual load. Thus, an output after training is accurate. Table 2 shows the comparison between the Absolute percentage error of the actual load and the predicted load. 
Figure 8. Forecast results for the month of March

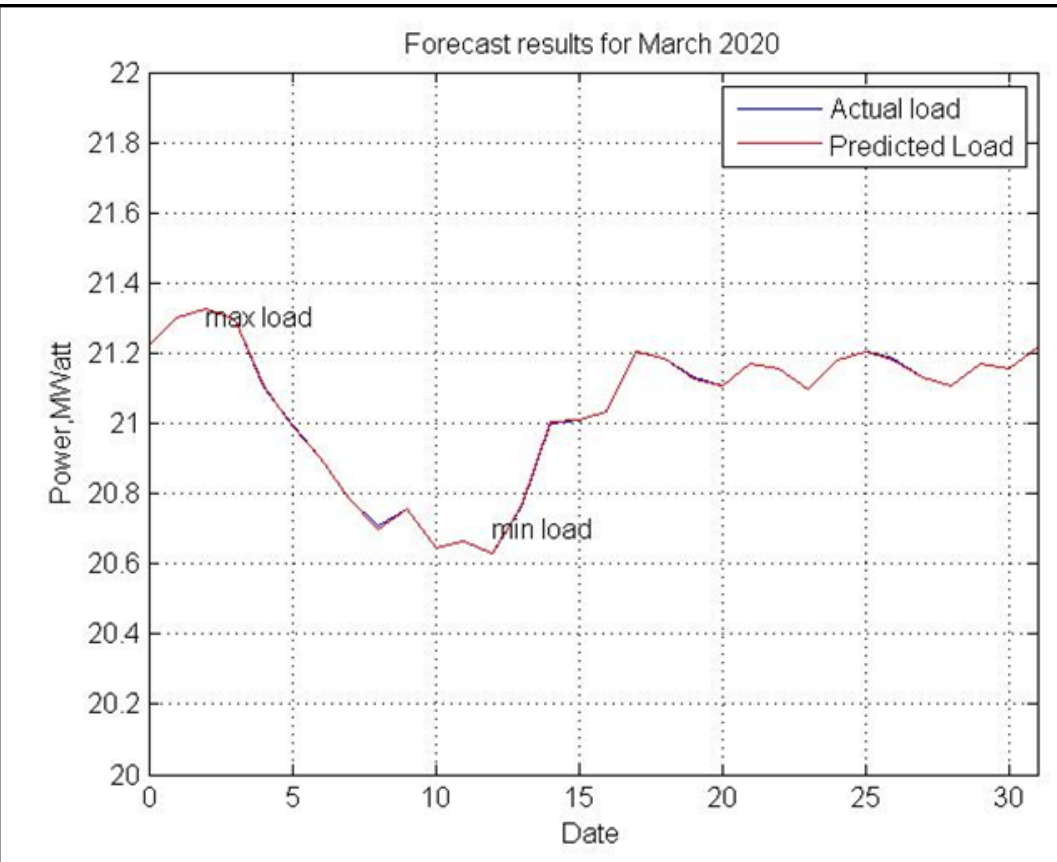

Table 2. Comparison between the Actual load and Predicted loa

\begin{tabular}{|c|c|c|c|c|}
\hline \multirow{2}{*}{ S No. } & \multirow{2}{*}{ Date } & \multicolumn{2}{|r|}{ Load in Megawatts } & \multirow{2}{*}{$\begin{array}{l}\text { Absolute } \\
\text { Percentage } \\
\text { error (\%) }\end{array}$} \\
\hline & & Actual load & Predicted load & \\
\hline 1. & 01-03-2020 & 21.221 & 20.906 & $1.484 \%$ \\
\hline 2. & 02-03-2020 & 21.299 & 20.785 & $2.413 \%$ \\
\hline 3. & $=03-2020$ & 21.328 & 20.710 & $2.897 \%$ \\
\hline 4. & 2020 & 21.295 & 20.761 & $2.507 \%$ \\
\hline 5. & -2020 & 21.104 & 20.655 & $2.127 \%$ \\
\hline 6. & $06-03-2020$ & 20.992 & 20.661 & $1.576 \%$ \\
\hline 7. & $07-03-2020$ & 20.900 & 20.629 & $1.29 \%$ \\
\hline 8. & 08-03-2020 & 20.785 & 20.763 & $0.105 \%$ \\
\hline 9. & 09-03-2020 & 20.708 & 21.001 & $1.414 \%$ \\
\hline 10. & $10-03-2020$ & 20.757 & 21.004 & $1.189 \%$ \\
\hline 11. & $11-03-2020$ & 20.643 & 21.031 & $1.879 \%$ \\
\hline 12. & $12-03-2020$ & 20.661 & 21.205 & $2.632 \%$ \\
\hline 13. & $13-03-2020$ & 20.628 & 21.185 & $2.700 \%$ \\
\hline 14. & 14-03-2020 & 20.763 & 21.125 & $1.743 \%$ \\
\hline 15. & $15-03-2020$ & 21.000 & 21.106 & $0.505 \%$ \\
\hline
\end{tabular}




\begin{tabular}{|c|c|c|c|c|c|}
\hline \multirow{2}{*}{ S No. } & \multirow{2}{*}{\multicolumn{2}{|c|}{ Date }} & \multicolumn{2}{|r|}{ Load in Megawatts } & \multirow{2}{*}{$\begin{array}{c}\text { Absolute } \\
\text { Percentage } \\
\text { error (\%) }\end{array}$} \\
\hline & & & Actual load & Predicted load & \\
\hline 16. & \multicolumn{2}{|l|}{$16-03-2020$} & 21.007 & 21.169 & $0.771 \%$ \\
\hline 17. & \multicolumn{2}{|l|}{$17-03-2020$} & 21.032 & 21.155 & $0.58 \%$ \\
\hline 18. & \multicolumn{2}{|l|}{$18-03-2020$} & 21.204 & 21.097 & $0.504 \%$ \\
\hline 19. & \multicolumn{2}{|l|}{ 19-03-2020 } & 21.184 & 21.179 & $0.024 \%$ \\
\hline 20. & \multicolumn{2}{|l|}{$20-03-2020$} & 21.130 & 21.204 & $0.350 \%$ \\
\hline 21. & \multicolumn{2}{|l|}{ 21-03-2020 } & 21.106 & 21.182 & $0.374 \%$ \\
\hline 22. & \multicolumn{2}{|l|}{$22-03-2020$} & 21.170 & 21.130 & $0.188 \%$ \\
\hline 23. & \multicolumn{2}{|l|}{ 23-03-2020 } & 21.157 & 21.108 & $0.231 \%$ \\
\hline 24. & \multicolumn{2}{|l|}{ 24-03-2020 } & 21.098 & 21.170 & $0.341 \%$ \\
\hline 25. & \multicolumn{2}{|l|}{$25-03-2020$} & 21.179 & 21.112 & $0.316 \%$ \\
\hline 26. & \multicolumn{2}{|l|}{ 26-03-2020 } & 21.204 & & $0.466 \%$ \\
\hline 27. & \multicolumn{2}{|l|}{ 27-03-2020 } & 21.184 & & $1.312 \%$ \\
\hline 28. & \multicolumn{2}{|l|}{$28-03-2020$} & 21.130 & & $1.632 \%$ \\
\hline 29 & \multicolumn{2}{|l|}{ 29-03-2020 } & 21.106 & 20.701 & $1.918 \%$ \\
\hline 30. & \multicolumn{2}{|l|}{$30-03-2020$} & & 1 & $1.955 \%$ \\
\hline 31. & $31-03-2020$ & 21.106 & & $0.075 \%$ & \\
\hline
\end{tabular}

The load forecasting by ANNis stuitable because of its various advantages. Moreover, the ANN is used for load forecasting because utilization of power output of CPP is fixed. The data was collected for all the 24 hours. The patterns include the features like load (MW), date, time, ambient air temperature from the compressor, coolair temperature at the compressor and IGV opening. The designed network is trained with supervised algorithm (Back propagation algorithm). Implementation of this network is showing reasonably good results with the Mean absolute Percentage Error (MAPE) of $1.210 \%$ which is very/ess. The error will be less by the use of large data set with very less variation. The result from the $A N N$ model reflects good prediction performance with a least error. Thus, short term load forecasting using ANN is an effective method for load forecasting.

\section{ACKNOWLEDGMENT}

My sincere gratitude goes to Yara Fertilizers, India Private Limited for providing required data and their contributions are sincerely appreciated and gratefully acknowledged. 


\section{REFERENCES}

Abiodun, O. I., Arshad, H., Dada, K. V., Jantan, A., Mohamed, N. A. E., \& Omolara, A. E. (2018). State-ofthe-art in artificial neural network Applications: A survey. Heliyo, 4(4). doi:10.1016/j.heliyon.2018.e00938 PMID:30519653

Alam, M. S., Islam, K. K., \& Halim, Z. E. (2013). Study on Gas Based Captive Power Generation in Bangladesh. Proceedings of 2013 2nd International Conference on Advances in Electrical Engineering, 19-21.

Araque, O., Corcuera Platas, I., Iglesias, C.A., \& Sanchez, J.F. (2017). Enhancing deep learning sentiment analysis with ensemble techniques in social application. Expert Syst. Appl., 77, 236-246.

Atlas, L. E., Damborg, M. J., El-Sharkawi, M. A., Marks, R. J., \& Park, D. C. (1991). Electric load forecasting using an artificial neural network. Institute of Electrical and Electronics Engineers, Transactions on Power Systems.

Baliyan, A., Kumar, G., \& Mishra, S. K. (2015). A Review of Short Term Load Forecasting using Artificial Neural Network Models. Elsevier Procedia Computer Science. doi:10.1016/j.procs.2015.04.160

Bello, I., Dibal, P., \& Harrison, I. (2015). Short Term Load Forecasting of 132/33Kv Maiduguri Transmission Substation Using Artificial Neural Networks. University of Maiduguri Computer Engineering Department.

Bello, I, \& Harrison, , I. (2015). Short Term Load Forecasting OF 132/33Kv Maiduguri Transmission Substation Using Artificial Neural Networks. University of Maiduguri Computer Engineering Department.

David, G. V., Debashish, B., Shukla, P. R., Tirthankar, N., Thomas, H., \& Yajnik, A. (2004). Captive Power Plants: Case Study of Gujarat, India. Programme on Energy and Sustainable Development Working Paper 22, Stanford University. Graziani, S., \& Xibilia, M. G. (2020). Innovative Topologies and Algorithms for Neural Networks. Future Internet, 12(117), 1-4.

Gupta, P., Mangalvedhekar, H.A., \& Mantri, R. (2013). Weather sensitive short term load forecasting using fully connected feed forward neural network. International Journal of Engineering Research and Technology.

He, W. (2017). Load Forecasting via Deep Neural Networks. Procedia Computer Science, 122, 308-314. doi:10.1016/j.procs.2017.11.374

Hippert, H. S., Pedreira, C. E., \& Souza, R. C. (2001) Neural networks for short term load forecasting: A review and evaluation. Institute of Electrical and Electronics Engineers.

Hippert, H. S., Pedreira, C. E., \& Souza, R. C.(2001). Neural networks for short term load forecasting: A review and evaluation. Institute of Electrical and Electronics Engineers.

Jaswal, R. N. (2013). Short Term Electric Load Prediction Using Artificial Neural Network. Kurukshetra University. Karthikeyan, V. Reddy C.. Sujatha, B., \& Veerendra, K. K. (2019). Power Load Forecasting using Back Propagation Algorithm. International Journal of Innovative Technology and Exploring Engineering.

Li, W., Liu, P., Liu, W. \& Zhang, Q. (2019). An improved approach for text sentiment classification based on a deep neural network via a sentiment attention mechanism. Future Internet, 11(4), 96. doi:10.3390/fi11040096

Liu, D., He, H., \& Wang, D. (2017). Adaptive critic nonlinear robust control: a survey. Institute of Electrical and Electronics Engineers, Trans. Cybern., 47(10), 3429-3451.

Ministry of Power. (2003). Discussion Paper on Rural Electrification Policies. Government of India.

Oak, R. A., \& Patil, D. B. (2016). Captive power plant- A case study of CEPT Ichalkaranji, Maharashtra. International Research Journal of Engineering and Technology.

Pooja, P. K., Rohit, C. C., Tushar, B. R., \& Tejaswini, V. K. (2018). Design Manufacturing \& Testing of Captive Power Plant Using Liquid Coolant Jet. International Journal of Innovative Research in Electrical, Electronics, Instrumentation and Control Engineering, 6(5), 34-39.

Sun, H., Xue, B., Zhao, H., \& Zhang, W. (2019). Embedded deep learning for ship detection and recognition. Future Internet, 11(2), 53. doi:10.3390/fi11020053

Tirthankar, N. (2010). Captive Generation in India-The Dilemma of Dualism. Infrastructure Report. 


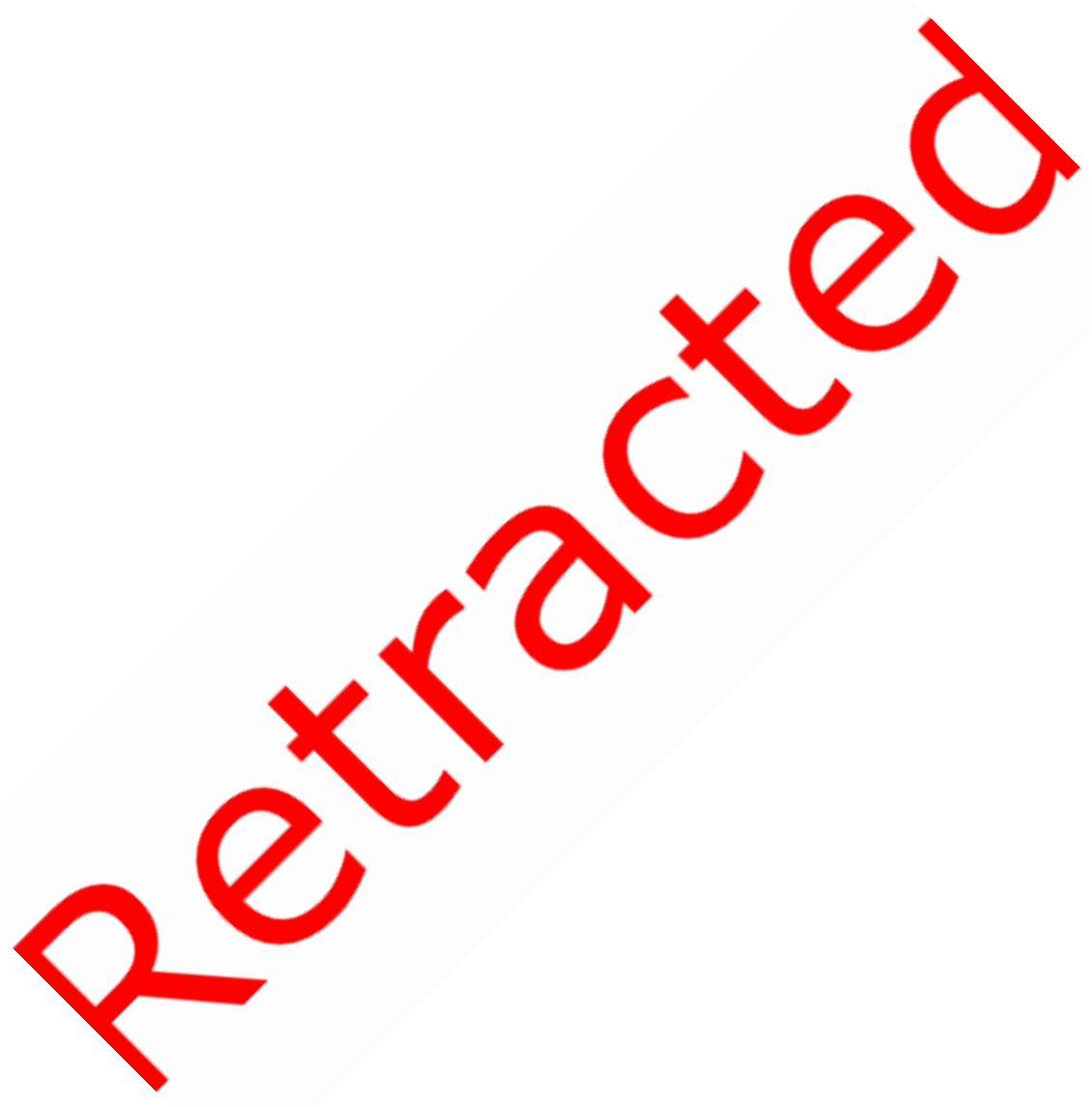

Kirti Pal is an Associate Professor in Electrical Engineering Department, School of Engineering, Greater Noida, India. She has total 14 year of teaching experience. Dr. Kirti holds a PhD degree in Electrical Engineering, 2013 from RGTU, Bhopal; M.E. degree from MITS Gwalior, 2006; BE degree from L.N.C.T. Bhopal, 2004. She has published many research and conference paper in various journal and conferences. She has guided project and dissertation work of many B. Tech and M.tech Students. Currently she is having 3 Ph.D students under his guidance. She has delivered many keynote and expert talks in national/international conferences/workshop. Her research areas are Restructuring of Power System, Power System Analysis and optimization, Soft Computing Techniques, Renewable Energy systems and Electric Vehicle. 